\title{
Coverage of azithromycin mass treatment for trachoma elimination in Northwestern Ethiopia: a community based cross-sectional study
}

Zelalem Tilahun and Teferi Gedif Fenta*

\begin{abstract}
Background: Mass drug administration with antibiotics predominantly with azithromycin is one of the four arms of the SAFE strategy. The elimination of ocular chlamydial infection is only achieved as long as the azithromycin mass treatments (AMT) are given frequently enough and at a high enough coverage. This study was conducted to assess the coverage of azithromycin mass treatment and its determinants in Awi Zone, Northwestern Ethiopia.

Methods: House to house survey using a structured questionnaire was done between July 7 to July 25, 2013. Coverage is defined as the proportion of individuals in the eligible population who actually ingested the Azithromycin during the Campaign.

Results: A total of 1267 households were enrolled in the survey in which 5826 eligible members were living in these households. Almost half (54.6\%) of the community members who were eligible for all six campaigns had participated in more than three campaigns of azithromycin mass treatment. The overall average self-reported coverage of the azithromycin mass treatment (AMT) in all six campaigns was $62.8 \%$ (64\% in rural vs. $61.6 \%$ urban). On average, each eligible person had taken the drug 3.77 times. The rural residents were significantly more likely to have received treatment during the last round of AMT in $2012\{\mathrm{AOR}=2.35 ; 95 \% \mathrm{Cl}$ [1.80-3.06]\}. Azithromycin uptake status of female household heads was less than the corresponding male household heads $\{A O R=0.41 ; 95 \% \mathrm{Cl}$ [0.24-0.72]\}. Household heads' awareness about trachoma (AOR $=2.55 ; 95 \% \mathrm{Cl}[1.19-5.44]$ ) and AMT $\{\mathrm{AOR}=7.19$; 95\% Cl [3.27-15.82]\} had positive association with acceptability.

Conclusion: The overall average AMT coverage was found to be low. There was low coverage of the treatment in the urban community as compared to the rural residents. Misconceptions of household heads about trachoma and azithromycin have negatively affected the coverage. Further work on why female household heads are associated with higher risk of non-participation in AMT is warranted. Strengthening awareness creation and consideration of additional campaigns is essential.
\end{abstract}

Keywords: Azithromycin mass treatment, Coverage, Trachoma elimination, Northwest Ethiopia

\footnotetext{
*Correspondence: tgedif@gmail.com; teferi.gedif@aau.edu.et

Social and Adminstrative Pharmacy Working Group, Departement of

Pharmaceutics and Social Pharmacy, College of Health Sciences, Addis Ababa

University, P.O.Box 1176, Addis Ababa, Ethiopia
}

(c) The Author(s). 2018 Open Access This article is distributed under the terms of the Creative Commons Attribution 4.0 International License (http://creativecommons.org/licenses/by/4.0/), which permits unrestricted use, distribution, and reproduction in any medium, provided you give appropriate credit to the original author(s) and the source, provide a link to the Creative Commons license, and indicate if changes were made. The Creative Commons Public Domain Dedication waiver (http://creativecommons.org/publicdomain/zero/1.0/) applies to the data made available in this article, unless otherwise stated. 


\section{Background}

"Trachoma, a neglected tropical disease, is the world's leading infectious cause of blindness" [1]. Globally, 1.2 billion people live in trachoma endemic areas; of these, $48.5 \%$ of the global burden is concentrated in Ethiopia, India, Nigeria, Sudan and Guinea [2]. In Ethiopia, approximately 67 million people are at risk for trachoma [3]. The Amhara National Regional State (ANRS) of Ethiopia was the most trachoma-endemic regional states in Ethiopia. Awi zone is one of the trachoma endemic zones among the 10 zonal administrations in ANRS with a TF and TT prevalence of 38.9 and $5.4 \%$, respectively [3, 4].

For many years, topical agents such as tetracycline were used as a treatment of choice for ocular infection with C.trachomatis because it is devoid of systemic side effects in children [5]. However, effective treatment requires that the drug be taken every day for four to six weeks [6]. Moreover because of its oily base, its use may be associated with blurred vision. Due to these reasons, compliance with these agents is poor [7].

Many randomized control trials indicated that azithromycin is the treatment of choice for ocular infection with C.trachomatis [2, 8-10]. Azithromycin is also associated with a short-term reduction in diarrheal morbidity in children $[11,12]$. It is easy to administer and higher coverage may be possible as compared to tetracycline topical treatment [13].

The World Health Assembly passed a resolution to eliminate blinding trachoma by implementing the "SAFE" ( $\mathrm{S}$ = surgery, $\mathrm{A}$ = antibiotic, $\mathrm{F}$ = facial cleanliness and $E=$ environmental improvement) strategy [14]. In Ethiopia the first strategic plan for trachoma control was developed in 2005 after a pilot trial of the SAFE strategy in four districts of ANRS. Then, ANRS Health Bureau partnering with the Lions Club of Ethiopia and the Carter Center had expanded trachoma control efforts from the four pilot districts to all districts with the SAFE strategy [3].

Mass drug administration with antibiotics predominantly with azithromycin is one of the four arms of the SAFE strategy. WHO had recommended communitywide distribution of oral azithromycin when the prevalence of trachomatous inflammation follicular (TF) is greater than $10 \%$ in children aged $1-9$ years, and trichiasis prevalence exceeding $1 \%$ in persons aged over 14 years [15]. Full participation is necessary for maximizing the impact of trachoma control programs [16]. Antibiotic distribution teams should offer azithromycin to all individuals over the age of six months in eligible communities. Overall coverage should be as high as possible, but treatment of $80 \%$ of the resident population should be the minimum target [17].

Unlike patient oriented treatments that are commonly self-initiated, there may not be full acceptance of the community for drugs that are given in the form of campaign due to different reasons $[18,19]$. In Ethiopia, even if there are many studies addressing the effectiveness of azithromycin mass treatment (AMT) for trachoma control, its acceptability and determinants has not been well explored. This study was therefore conducted to assess the acceptability of the azithromycin mass treatment and its determinants in Awi zone, Northwestern Ethiopia.

\section{Methods}

\section{Study area and design}

A community based cross sectional survey was conducted following 6 AMT rounds in both urban and rural kebeles (the smallest administrative units in the government structure) of Injibara town and Adjacent Banja districts from July 7 to July 25, 2013.

\section{Study participants}

All individuals living in Injibara town and Banja districts were taken as source population. The study population was all individuals who live in the selected two urban and six rural kebeles. All family members who lived more than 8 months in that household during the time of the survey were included. All children who were older than 6 months during 2012 AMT program were also taken as study participants.

\section{Sample size determination}

The number of households to be involved in the survey was determined using the single proportion formula [20]. The sample size was calculated with the assumption that the level of coverage was 0.5 and the absolute sampling error to be tolerated as 0.04 with $95 \%$ confidence interval. Taking the experiences of similar African Studies the design effect of 2 was considered to calculate the sample size [21]. Adding 10\% for non-responses, a total of 1321 households were included.

\section{Sampling method}

The number of households covered in urban and rural kebeles were allocated based on proportionate to the size of population established in 2007 CSA census $(28 \%$ Urban and 72\% Rural) [22]. Accordingly, six rural and two urban kebeles were randomly selected. Finally, the number of households in each kebele was determined proportionate to the size of households in each kebele and specific households were selected using a systematic random sampling technique.

\section{Operational definition}

\section{Coverage}

Coverage is defined as the proportion of individuals in the sampled population who actually ingested the Azithromycin during the Campaign. 


\section{Azithromycin mass treatment (AMT)}

It is an annual mass administration of azithromycin to all eligible community members (children less than 6 months old are excluded) for the purpose of trachoma elimination. Six rounds of mass distribution were conducted by Health Extension Workers in the Districts and the last campaign was in November 2012.

\section{Serious adverse effects}

An adverse experience following AMT that results in death, life threatening condition, in-patient hospitalization, disability and/or birth defects.

\section{Data collection instruments}

Adult household members were interviewed with a pretested structured questionnaire (attached as Additional file 1 ) by 13 trained data collectors. The structured questionnaire was translated to Amharic (official language) and most of the interview was done using Amharic. For those participants who couldn't speak and understand Amharic, interview was done using the local language. The head of each household was interviewed about himself and eligible children less than 18 years old as well as for family members who were absent during the data collection time. Data collectors with health background were carefully selected and given training on how to administer the questionnaire to avoid possible interviewer bias.

\section{Data analysis and interpretation}

Data was coded and entered into Epi Info version 3.5.3 by three trained data entry clerks. Then, the data was transferred to SPSS version 20.0 and analyzed. Socio-demographic variables including sex, age, marital status, educational status, occupation and place of residence, and awareness about AMT were considered as independent variables and frequency of self reported AMT coverage as outcome variable. In addition to simple descriptive statistics, chi square test, correlation and logistic regression analysis were conducted to show possible associations. $P$-value $<0.05$ was considered as statistically significant.

\section{Results}

A total of 1321 households were enrolled in the survey. Complete questionnaires were obtained from 1267 households; making a response rate of $96 \%$. All members in the 1267 households who fulfilled the inclusion criteria were included and hence a total of 5826 eligible household members were considered in the subsequent analysis. Among these, 5266 (90.4\%) were greater than or equal to 7 years old at the time of the survey and anticipated as eligible for all six rounds.

\section{Socio-demographic characteristics}

Among the total 1267 households included in the study, $897(70.8 \%)$ of them were from rural areas. Most of the household heads 973 (76.8\%) were males. The mean age of household heads was $46.3 \pm 14.2$. The mean age of the AMT eligible participants was $25.1 \pm 17.64$. More than half of the participants were less than 20 years (Table 1 ).

\section{Household heads' awareness and perception about trachoma}

Among the total 1267 household heads, 1203 (94.9\%) had ever heard about trachoma. The main information source for most of the household heads about trachoma was health professionals 1076 (89.44\%) followed by neighbors 87 (7.23\%). Poor environmental sanitation was mentioned by 717 (59.6\%) of them as a cause of trachoma. Among 1203 household heads who had ever heard about trachoma, 428 (35.6\%) mentioned fly as a way of transmission; 401 (33.3\%) of them did not know the way of trachoma transmission whereas 22 (1.8\%) household heads believed that trachoma is a non-communicable disease. But a sizable proportion 1084 (90\%) believed that trachoma is a preventable disease. However, 77 (7.1\%) of them did not know any prevention methods for trachoma.

Household heads' awareness and perception about AMT From the total household heads participated in the survey, 1234 (97.4\%) of them had ever heard about AMT administrated for the elimination of trachoma. Among these, 1117 (90\%) had heard about it from health professionals. Almost all of them 1263 (99.7\%) reported that mass drug treatment had ever been given in their kebeles even though some of them were not aware about the treatment and its purpose. Of the total respondents, $150(11.8 \%)$ believed that the drug was not given based on free will. Among the total household heads participated in the study, 1204 (95\%) reported that they would volunteer to participate in the mass treatment if it was to be continued in the future. The most frequently mentioned reasons to end their participation to AMT by the rest of 63 (5\%) household heads were fear of illness and death by the drug, serious side effect in previous campaign, having chronic illness, and absence of change to their eye health.

\section{Self-reported azithromycin mass treatment coverage}

In 1240 (97.9\%) of the households, it was reported that at least one member had ever participated in any rounds of the campaign and the rest $27(2.1 \%)$ claimed that none of the members had ever taken AMT. Being absent from home during the campaigns, health problems, and fear of the severe side effects were the major reasons mentioned for non-participation in AMT. 
Table 1 Socio demographic distribution of the study participants, Injibara town and Banja districts of Awi zone, Northwestern Ethiopia, July 2013

\begin{tabular}{|c|c|c|c|}
\hline $\begin{array}{l}\text { Socio demographic } \\
\text { variables } N=5826\end{array}$ & $\begin{array}{l}\text { Urban } \\
\text { residents }\end{array}$ & $\begin{array}{l}\text { Rural } \\
\text { residents }\end{array}$ & $\begin{array}{l}\text { Total } \\
n(\%) \\
\end{array}$ \\
\hline \multicolumn{4}{|l|}{ 1. Sex } \\
\hline Male & 706 & 2172 & $2878(49.4)$ \\
\hline Female & 804 & 2144 & $2948(50.6)$ \\
\hline \multicolumn{4}{|l|}{ 2. Age } \\
\hline $1-5$ years & 135 & 318 & $453(7.8)$ \\
\hline $6-10$ years & 208 & 608 & $813(14)$ \\
\hline $11-15$ years & 207 & 727 & $934(16)$ \\
\hline $16-20$ years & 224 & 696 & $920(15.8)$ \\
\hline $21-40$ years & 537 & 1066 & $1603(27.5)$ \\
\hline $41-60$ years & 169 & 671 & $840(14.4)$ \\
\hline$>60$ years & 30 & 233 & $263(4.5)$ \\
\hline \multicolumn{4}{|l|}{ 3. Occupation } \\
\hline Student & 635 & 1679 & $2314(39.7)$ \\
\hline Farmer & 51 & 1791 & $1842(31.6)$ \\
\hline Merchant & 100 & 45 & $145(2.5)$ \\
\hline Government employee & 245 & 36 & $281(4.8)$ \\
\hline House wife & 182 & 181 & $363(6.2)$ \\
\hline Jobless & 56 & 32 & $88(1.5)$ \\
\hline Others $^{\mathrm{a}}$ & 241 & 552 & $793(13.6)$ \\
\hline \multicolumn{4}{|l|}{ 4. Religion } \\
\hline Orthodox & 1497 & 4276 & $5773(99.1)$ \\
\hline Muslim & 0 & 8 & $8(0.13)$ \\
\hline Protestant & 13 & 1 & $14(0.24)$ \\
\hline Others $^{\mathrm{b}}$ & 0 & 31 & $31(0.53)$ \\
\hline \multicolumn{4}{|l|}{ 5. Educational Status } \\
\hline Unable to read and write ${ }^{c}$ & 336 & 1970 & $2306(39.6)$ \\
\hline Able to read and write & 97 & 322 & $419(7.2)$ \\
\hline Grade 1-4 & 167 & 604 & $771(13.2)$ \\
\hline Grade 4-8 & 356 & 964 & $1320(22.6)$ \\
\hline Grade $9-12$ & 261 & 412 & $673(11.6)$ \\
\hline College and Above & 293 & 44 & $337(5.8)$ \\
\hline \multicolumn{4}{|l|}{ 6. Marital Status } \\
\hline Single ${ }^{d}$ & 871 & 2562 & $3433(58.9)$ \\
\hline Married & 573 & 1562 & $2135(36.7)$ \\
\hline Divorced & 32 & 86 & $118(2.0)$ \\
\hline Widowed & 34 & 106 & $140(2.4)$ \\
\hline
\end{tabular}

From the total 5266 (90.4\%) household members who were eligible for all campaigns, only 2876 (54.6\%) of them claimed to have participated more than three times out of the six rounds of AMT campaigns. The overall average self-reported coverage of the AMT in all six campaigns was $62.8 \%$ (64\% rural and $61.6 \%$ urban). On average, each eligible person participated 3.77 times. From the total 560 children who were not eligible for all campaigns, 75 children were less than 1 year old and expected to participate in the campaign once. Of these, only $54(72 \%)$ were taken the treatment. From 1510 AMT urban household members enrolled in the study, 1344 (89\%) were eligible for all campaigns. Of these 78 $(5.8 \%)$ of them had never participated and only 72 (27.7\% completed the six rounds of AMT (Fig. 1).

The self-reported AMT coverage of the 2012 campaign was 92.9\%; whereas a report obtained from District Health Office indicated that the coverage was close to $96 \%$.

Out of the total 1227 household heads who had ever taken azithromycin, 1166 (95\%) believed that AMT was beneficial. Among those who said AMT is beneficial, 978 (83.9\%) related the benefit to eye health; 481 (41.3\%) for eradicating intestinal worm; and 15 (1.3\%) for improving the general health. Other benefits such as treatment for hemorrhoid and stimulating appetites were mentioned by $5(0.4 \%)$ of the respondents.

\section{Reported side effects with AMT use}

From the total 1227 household heads who had ever taken the drug, 538 (43.9\%) reported to have had side effects of azithromycin. Anal burning sensation, diarrhea, and heartburn were the three most prevalent side effects reported (Fig. 2).

Out of the total 538 household heads who had ever encountered side effects of azithromycin, 83 (15.4\%) had claimed that they experienced with serious adverse effects of the drug. In addition, 296 (23.4\%) of the household heads had heard other persons complaining about the drug's side effects. Of which, 88 (29.7\%) of them reported that they had ever heard about serious adverse effects of the drug such as birth defect, inpatient hospitalization and disability. From this, 38 (43.2\%) of them reported that they knew persons who encountered with at least one of the serious adverse effects of the drug.

From the total 1227 household heads who had ever participated in AMT, 66 (5.4\%) of them used the drug for different purposes other than trachoma such as for treating intestinal worms, promote animal fertilization and for the relief of abdominal pain.

\section{Determinants of the 2012 azithromycin mass treatment coverage}

The 2012 Azithromycin uptake was not found to be influenced by socio demographic characteristics, except job. Students' participation in the mass treatment 


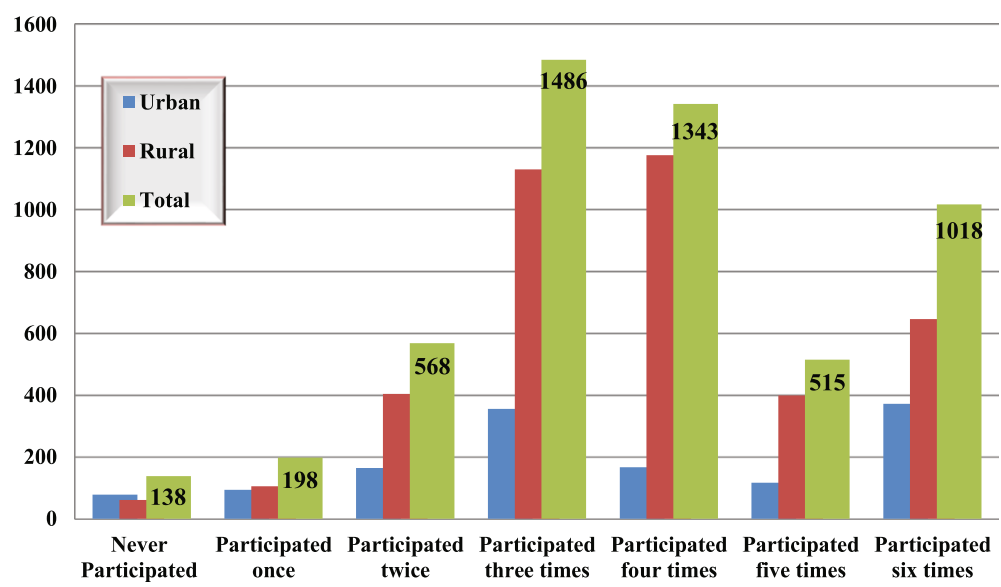

Fig. 1 Frequency of AMT self-reported uptake among urban and rural household members in Injibara town and Banja districts of Awi Zone, July 2013

was higher as compared to farmers, merchants and others. Place of residence affects the drug uptake status. In this regard, the proportion of eligible rural residents who took AMT more than three times was $56.7 \%$ and for urban residents, it was $48.7 \%$. This difference was statistically significant $\{\mathrm{AOR}=2.35$, 95\% CI [1.80-3.06]\}.

There was a significant difference between the rural residents and urban residents in the number of times they took azithromycin. Higher number of rural residents had taken azithromycin more than 3 times as compared to urban residents $\{\mathrm{AOR}=1.69 ; 95 \% \mathrm{CI}$ [1.44-1.98]\}. There was no significant difference in frequency of AMT uptake between males and females. There was a significant difference in the frequency of AMT uptake among children ages between 7 to 10 years compared to other age groups. In this regard, the proportion of adults with age between 16 and 20 years who took azithromycin more than 3 times was higher than in children with age between 7 to 10 years $\{\mathrm{AOR}=2.77$; 95\% CI [2.15-3.57]\}. Similarly, the study participants who were older than 20 years were at better enactment in taking azithromycin more than 3 times as compared to children less than 15 years. There was also a positive correlation between the number of times they took azithromycin and age $(r=0.235$; $95 \% \mathrm{CI}, p=0.01$ ). As age increased, participation in AMT increased but being literate had no effect in participation rate (Table 2).

\section{Factors associated with participation in the 2012AMT}

The self-reported participation rate of rural household heads in the 2012 mass treatment was higher than their urban counterparts (AOR $=2.33$; 95\% CI $[1.07-5.10]$ ). Azithromycin uptake status of female household heads was significantly less than the corresponding male

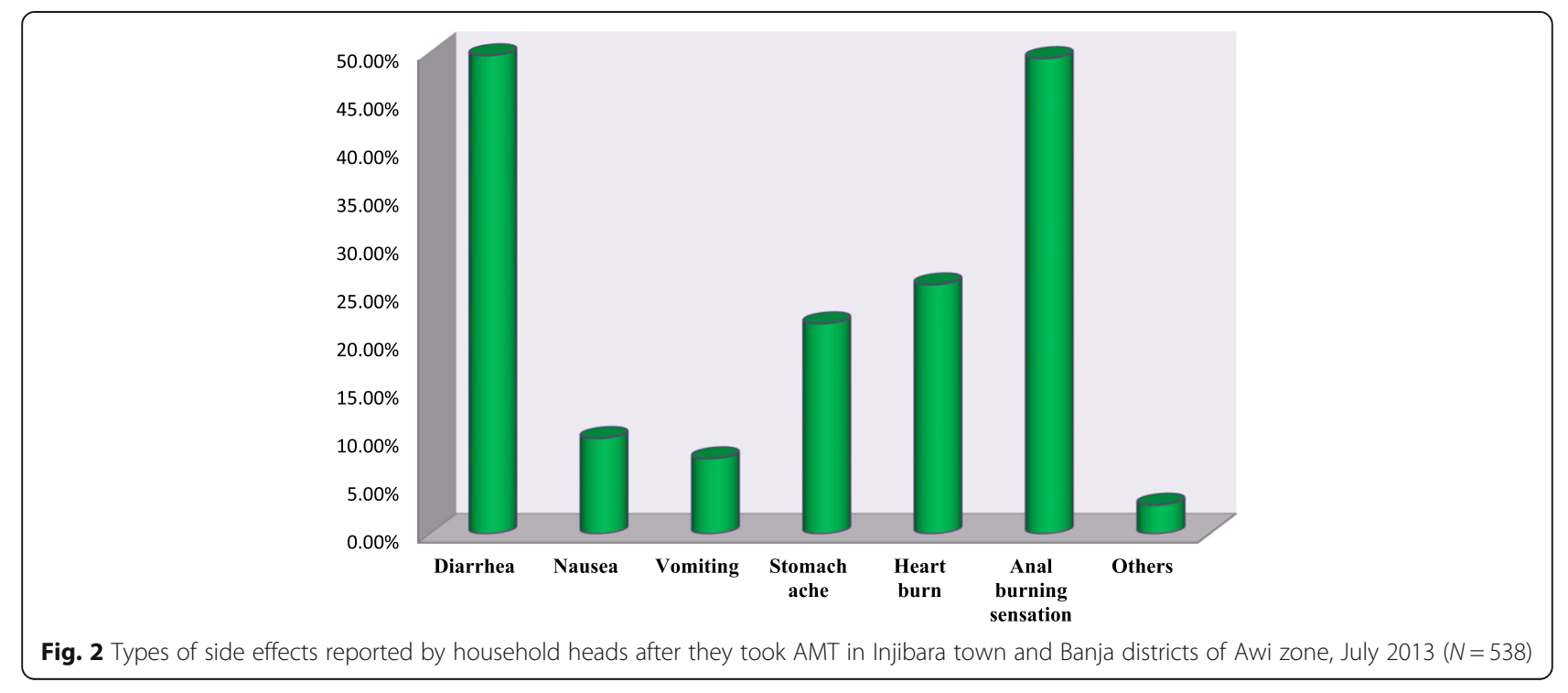


Table 2 Socio demographic factors associated with the frequency of AMT uptake among eligible participants to all campaigns, in Injibara town and Banja districts of Awi zone, July 2013

\begin{tabular}{|c|c|c|c|c|}
\hline \multirow{2}{*}{$\begin{array}{l}\text { Socio demographic } \\
\text { variables }[N=5266]\end{array}$} & \multicolumn{2}{|c|}{ Frequency of AMT uptake } & \multicolumn{2}{|c|}{ 95\% Confidence Interval } \\
\hline & $>3$ Times & $\leq 3$ Times & $\overline{C O R}$ & $\mathrm{AOR}$ \\
\hline \multicolumn{5}{|l|}{ Residence } \\
\hline Rural & 2222 & 1700 & $1.37[1.22-1.56]$ & $1.69[1.44-1.98]$ \\
\hline Urban & 654 & 690 & 1.00 & \\
\hline \multicolumn{5}{|l|}{ Sex } \\
\hline Female & 1450 & 1217 & 0.98 [0.88-1.09] & $0.92[0.82-1.04]$ \\
\hline Male & 1426 & 1173 & 1.00 & \\
\hline \multicolumn{5}{|l|}{ Age } \\
\hline$>60$ years & 165 & 98 & $3.70[2.75-4.97]$ & $4.40[2.96-6.56]$ \\
\hline $41-60$ years & 532 & 309 & $3.78[3.06-4.67]$ & $4.71[3.38-6.58]$ \\
\hline $21-40$ years & 968 & 634 & $3.35[2.78-4.04]$ & $4.04[3.01-5.42]$ \\
\hline $16-20$ years & 543 & 377 & $3.16[2.47-3.89]$ & $2.77[2.15-3.57]$ \\
\hline $11-15$ years & 447 & 487 & $2.01[1.64-2.47]$ & $1.76[1.40-2.22]$ \\
\hline $7-10$ years & 221 & 485 & 1.00 & 1.00 \\
\hline \multicolumn{5}{|l|}{ Job } \\
\hline Farmer & 1074 & 734 & $1.45[1.28-1.64]$ & $1.04[0.81-1.33]$ \\
\hline Merchant & 83 & 62 & $1.32[0.94-1.86]$ & $1.03[0.70-1.52]$ \\
\hline Government employee & 156 & 125 & $1.23[0.96-1.58]$ & $0.94[0.62-1.43]$ \\
\hline Housewife & 234 & 129 & $1.79[1.42-2.26]$ & $1.49[1.08-2.06]$ \\
\hline Jobless & 48 & 40 & $1.19[0.77-1.82]$ & $1.00[0.63-1.58]$ \\
\hline Others & 140 & 173 & $0.80[0.630 .28-1.04]$ & $0.77[0.58-1.03]$ \\
\hline Student & 1141 & 1127 & 1.00 & 1.00 \\
\hline \multicolumn{5}{|l|}{ Educational Status } \\
\hline College and above & 183 & 154 & $0.87[0.69-1.10]$ & $1.26[0.85-1.85]$ \\
\hline Grade 9-12 & 416 & 257 & 1.19 [0.99-1.43] & $1.78[1.39-2.28]$ \\
\hline Grade 4-8 & 712 & 607 & $0.86[0.75-0.99]$ & $1.21[0.98-1.50]$ \\
\hline Grade 1-4 & 288 & 449 & $0.47[0.40-0.56]$ & $0.62[0.49-0.78]$ \\
\hline Able to read and write & 240 & 162 & $1.09[0.87-1.36]$ & $1.01[0.79-1.28]$ \\
\hline Unable to read and write & 1037 & 761 & 1.00 & 1.00 \\
\hline \multicolumn{5}{|l|}{ Marital Status } \\
\hline Married & 1277 & 853 & $1.51[1.35-1.69]$ & $1.41[1.15-1.74]$ \\
\hline Divorced & 79 & 39 & $2.05[1.38-3.02]$ & $1.89[1.21-2.94]$ \\
\hline Widowed & 88 & 52 & $1.71[1.20-2.43]$ & $1.54[1.02-2.34]$ \\
\hline Single & 1432 & 1446 & 1.00 & 1.00 \\
\hline
\end{tabular}

household heads $\{\mathrm{AOR}=0.41 \quad 95 \%$ CI $[0.24-0.72]\}$. Occupation, educational status and marital status of household heads did not affect their uptake status. However, their participation was influenced by their awareness and perception about AMT. For example, those household heads who had ever heard about AMT were more likely participated in the 2012 campaign as compared to those who were unaware $\{$ AOR $=7.19 ; 95 \%$ CI [3.27-15.82]\}. In addition, the proportion of household heads who believed that AMT was given on free will and had participated in 2012 mass campaign was more than the proportion of those who considered AMT as an obligation $\{\mathrm{AOR}=2.93$; 95\% CI $[1.77-4.86]\}$ (Table 3).

\section{Discussion}

The 2012 self reported azithromycin mass treatment coverage was $92.9 \%$. This was higher than $80 \%$, the minimum attainable coverage set by WHO [17]. This finding was also higher than $76 \%$ taken from the mass treatment 
Table 3 Association between awareness about AMT and selfreported uptake status of household heads in 2012, Awi Zone, July 2013

\begin{tabular}{llll}
\hline Variables & \multicolumn{1}{l}{ Took 2012 AMT } & & $95 \%$ Confidence Interval \\
\cline { 2 - 3 } \cline { 1 - 1 } No & & COR AOR
\end{tabular}

Heard about AMT

$\begin{array}{lllll}\text { Yes } & 1125 & 109 & 10.97[5.39-22.32] & 7.19[3.27-15.82] \\ \text { No } & 16 & 17 & 1.00\end{array}$

Did they Know why AMT given in free?

$\begin{array}{lllll}\text { Yes } & 764 & 79 & 1.21[0.82-1.77] & 0.97[0.63-1.48] \\ \text { No } & 377 & 47 & 1.00 & 1.00\end{array}$

Was the treatment given to those willing to take?

$\begin{array}{lllll}\text { Yes } & 1024 & 93 & 3.11[2.0-4.83] & 2.93[1.77-4.86] \\ \text { No } & 117 & 33 & 1.00 & 1.00\end{array}$

Did they think that the drug is beneficial for trachoma?

$\begin{array}{lllll}\text { Yes } & 1100 & 87 & 12.03[7.37-19.63] & 7.33[4.13-13.02]\end{array}$

$\begin{array}{lllll}\text { No } & 41 & 39 & 1.00 & 1.00\end{array}$

Did they experience any side effects' of the drug?

$\begin{array}{lllll}\text { Yes } & 495 & 43 & 1.00 & 1.00 \\ \text { No } & 646 & 43 & 1.31[0.84-2.02] & 1.40[0.87-2.26]\end{array}$

Had they got SAE of the drug?

$\begin{array}{lllll}\text { Yes } & 75 & 8 & 0.78[0.35-1.75] & 0.87[0.35-2.12] \\ \text { No } & 419 & 35 & 1.00 & 1.00\end{array}$

Heard drug's side effects from other Persons?

$\begin{array}{lllll}\text { Yes } & 257 & 39 & 1.00 & 1.00 \\ \text { No } & 884 & 87 & 1.54[1.03-2.31] & 1.34[0.78-2.32]\end{array}$

Did they know a person with SAE of the drug?

$\begin{array}{lllll}\text { Yes } & 32 & 6 & 1.02[0.32-3.22] & 1.16[0.24-5.57] \\ \text { No } & 42 & 8 & 1.00\end{array}$

Did treatment providers provide any information?

$$
\begin{array}{lllll}
\text { Yes } & 852 & 40 & 3.39[2.17-5.29] & 2.49[1.53-4.08] \\
\text { No } & 289 & 46 & 1.00
\end{array}
$$

Willingness to take the drug in the future

\begin{tabular}{lllll} 
Yes & 1113 & 91 & $15.29[8.90-26.26]$ & $5.78[2.44-13.68]$ \\
No & 28 & 35 & 1.00 & \\
\hline
\end{tabular}

SAE Serious adverse effect

coverage in Tanzania [19]; and the mean treatment coverage in 48 eligible communities in four Gambian districts taken at baseline, and after one and two years [21].

The overall self-reported coverage of AMT for the six campaigns in the study area was estimated based on the number of times that each eligible household member had taken the treatment. In this regard, the proportion of eligible household members for all campaigns who took azithromycin more than three times out of the six rounds was $54.6 \%$. The reported mean number of times that each person had taken azithromycin was $3.77 \pm 1.51$. Even though the self-reported coverage might be liable to recall bias, the 2012 AMT data obtained from the official records of the district health office was higher than the self-reported coverage for the same year (96\% vs. 92.8\%). A similar type of discrepancy was observed in a study conducted in Plateau State of Nigeria, in which only $60.3 \%$ of the participants reported to have received azithromycin or tetracycline eye ointment during mass drug administration but the coverage report taken from administrative data was $75.8 \%$ [23]. The reasons for such differences should be explored in the future.

There was a report from the community that the drug manifested side effects. Consequently, even all the community members who had received the drug might have not taken it; resulting a decrease in the overall actual coverage below the minimum WHO target [17]. This may have negative impact in the program success as intended elimination can only occur if the mass treatment is given frequently enough and at a high coverage. This is due to the fact that treatment of few persons in endemic areas may result in reinfection from family or neighborhood sources unless the treatment is more widespread [24-26]. Therefore, the present study finding is an indicative of the need for determining the prevalence of TF and consider additional campaigns of AMT in the studied communities.

This study also showed that the proportion of eligible rural residents who took azithromycin more than three times in the six campaigns was higher as compared to urban residents $(\mathrm{AOR}=1.69 ; 95 \% \mathrm{CI}[1.44-1.98])$. Better acceptance and coverage of the program in the rural community is more appreciable since the prevalence of trachoma in the rural population showed a fourth fold increase as compared to the urban [4].

Older age groups were more likely to participate in AMT than the younger age group. A bivariate correlation analysis also showed that there is positive correlation between the number of times they participated in AMT campaigns and age. It was also noted that low uptake among children in the present study was in contrary to widely advocated goal that high coverage should be attained in children less than 15 years [16, 17]. This is due to the fact that the average duration of trachoma infection at younger ages is long since tears and secretions infected with chlamydia are easily and frequently swapped among the young preschool children and their caretakers, which leads to repeated episodes of reinfection [27, 28].

Out of the total 1227 household heads who had ever taken the drug, 538 (43.9\%) of them reported to have experienced side effects of azithromycin. Among these, $83(15.4 \%)$ of them claimed that they had serious adverse effect of the drug. Another study conducted in Ethiopia reported that the prevalence of adverse events ranged 
4.9-7.0\% in children of $1-9$ years of age and $17.0-18.7 \%$ in persons $\geq 10$ years of age [29]. As it is pointed out in a recent study, patients taking azithromycin had an increased risk of cardiovascular death as compared to those who didn't take [30, 31]. Another very recent meta-analysis of observational studies of 5 cohorts evidenced that azithromycin use was not associated with higher risk of death particularly in younger population whereas older population might be at higher risk of death $(\mathrm{HR}=1.64$ (CI, 1.232.19), $I=4 \%)$ [32]. Giving careful consideration on the safety impact of the mass treatment in special population such as elderly and patients with co-morbidity is mandatory [33].

Prior awareness of household heads' about AMT has a positive association with the drug uptake $(\mathrm{AOR}=7.19$; 95\% CI [3.27-15.82]). Household heads who thought that the mass treatment is beneficial were more likely to take the treatment as compared to those who believed the opposite (AOR $=7.33$; 95\% CI [4.13-13.02]). Another study documented that increased knowledge about the drugs given in mass treatment and their side effects may result in a better perception of its benefits than its barriers [34]. Hence adequate health education as well as awareness creation programs should precede the mass treatment campaigns for better coverage and acceptability of the treatment program.

\section{Limitations of the study}

The study depended on the report of household heads on the participation of himself or herself and other eligible household members in the six rounds of AMT campaigns. The accuracy of the response therefore depends on the ability of the respondents to recall. Hence our study was liable to recall bias. In addition the focus group discussion we had before the survey showed that there was a great public concern on the adverse effect of azithromycin in the first round of the campaigns. This public concern could have affected how respondents answered the survey, especially with regards to adverse events.

\section{Conclusion}

The overall average self-reported coverage of AMT in all six campaigns was low. There is low coverage and acceptability of the treatment in the urban community as compared to the rural residents. Being female and urban resident and low awareness about trachoma and azithromycin have negatively affected the acceptability of the AMT by household heads and hence the coverage. Awareness creation and health education programs about trachoma and AMT are needed for effective implementation of trachoma elimination programs. Further work on why female household heads are associated with higher risk of non-participation in AMT is also warranted.

\section{Additional file}

Additional file 1: Questionnaires used in the survey. (PDF 37 kb)

\section{Abbreviations}

AMT: Azithromycin mass treatment; ANRS: Amhara National Regional States; AOR: Adjusted odds ratio; COR: Crude odds ratio; TF: Trachomatous inflammation follicular; TT: Trachomatous trichiasis

\section{Acknowledgements}

The authors acknowledge Graduate Program of Addis Ababa University for funding this research project. We are also thankful to the Staffs of Carter Center (Ethiopia Office) for their technical assistance and data collectors and data entry clerks for their devoted work.

\section{Funding}

Graduate Program of Addis Ababa University funded the research. The funders had no role in study design, data collection and analysis, decision to publish, or preparation of the manuscript.

\section{Availability of data and materials}

All the data generated and analyzed during this study are available from the first Author and stored in SPSS software. However, it may not be shared for ethical reasons.

\section{Authors' contributions}

Both ZT and TGF designed the research. ZT supervised the data collection process, analyzed the data and drafted the report. TGF critically reviewed the report. Both Authors approved the manuscript.

\section{Ethics approval and consent to participate}

Before the study began, all procedures and methods planned was reviewed and approved by the Ethics Review Committee of the School of Pharmacy, Addis Ababa. Then, official letter was written from the Department of Pharmaceutics and Social Pharmacy to Amhara Regional Health Bureau to get permission for conducting the study. The purpose of the study was clearly explained to all study participants, and verbal informed consent was obtained from each participant.

\section{Consent for publications}

Not applicable.

\section{Competing interests}

All authors declared that there are no competing interests.

\section{Publisher's Note}

Springer Nature remains neutral with regard to jurisdictional claims in published maps and institutional affiliations.

Received: 16 October 2017 Accepted: 25 July 2018

Published online: 06 August 2018

\section{References}

1. WHO. WHO Alliance for Global Elimination of Blinding Trachoma by 2020: Weekly epidemiological record 2014; 39(89):421-428.

2. Mariotti SP, Pascolini D, Rose-Nussbaumer J. Trachoma: global magnitude of a preventable cause of blindness. Br J Ophthalmol. 2009;93:563-8.

3. Carter Center. Summary Proceedings: Eleventh Annual Trachoma Control Program Review; Planning for Trachoma Elimination, District by District; 2010.URL: http://www.cartercenter.org/resources/pdfs/news/health_ publications/trachoma/trachreview_final_eng2010.pdf (Accessed on December 2012).

4. $\mathrm{FMOH}$. National survey on blindness, Low Vision and Trachoma in Ethiopia; 2006. http://pbunion.org/Countriessurveyresults/Ethiopia/Ethiopian_ National_Blindness_and_trachoma_survey.pdf (Accessed on 05 DeC 2012).

5. Darougar S, Jones BR, Viswalingam M, et al. Topical therapy of hyper endemic trachoma with rifampicin, oxytetracycline or spiramycin eye ointments. Br J Ophthalmol. 1980;64:37-42. 
6. Dawson CR, Daghfous T, Hoshiwara I, et al. Trachoma therapy with topicaltetracycline and oral erythromycin: a comparative trial. Bull World Health Organ. 1982;60:347-55.

7. West SK, Solomon AW. Azithromycin for control of trachoma. Community Eye Health. 1999;12:55-6.

8. Bailey RL, Arullendran P. Whittle HC, Mabey DC. Randomized controlled trial of single-dose azithromycin in treatment of trachoma. Lancet. 1993;342:453-6.

9. Solomon AW, Holland MJ, Alexander NDE, Massae PA, Aguirre A, NatividadSancho A, Molina S, Safari S, Shao JF, Courtright P, Peeling RW, West SK, Bailey RL, Foster A, Mabey DC. Mass treatment with single dose azithromycin for trachoma. N Engl J Med. 2004;351:1962-71.

10. Solomon AW, Harding-Esch E, Alexander ND, Aguirre A, Holland MJ, Bailey RL, Foster A, Mabey DC, Massae PA, Courtright P, Shao JF. Two doses of azithromycin to eliminate trachoma in a Tanzanian community. New Engl J Med. 2008;358:1870-1.

11. Coles CL, Seidman JC, Levens J, Mkocha H, Munoz B, West S. Association of Mass Treatment with azithromycin in trachoma-endemic communities with short-term reduced risk of diarrhea in young children. Am J Trop Med Hyg. 2011; https://doi.org/10.4269/ajtmh.2011.11-0046.

12. Keenan JD, Ayele B, Gebre T, Zerihun M, Zhou Z, House Jl, Gaynor BD, Porco TC, Emerson PM, Lietman TM. Childhood mortality in a cohort treated with mass azithromycin for trachoma. Clin Infect Dis. 2011;52:883-8.

13. Fraser-Hurt N, Bailey RL, Cousens S, Mabey D, Faal H, Mabey DCW. Efficacy of oral azithromycin versus topical tetracycline in mass treatment of endemic trachoma. Bull World Health Organ. 2001;79:632-40

14. WHO. World Health Assembly Resolution 51.11 Global Elimination of blinding trachoma; 1998. http://www.who.int/neglected_diseases/ mediacentre/WHA_51.11_Eng.pdf. Accessed 30 Nov 2012.

15. WHO-ITI. Joint Research Agenda Meeting for the Elimination of Blinding Trachoma. Geneva: World Health. Organization; 2004.

16. Ssemanda EN, Levens J, Mkocha H, Munoz B, West SK. Azithromycin Mass Treatment for Trachoma Control: Risk Factors for Non-Participation of Children in Two Treatment Rounds. PLoS Negl Trop Dis. 2012; https://doi. org/10.1371/journal.pntd.0001576.

17. Melese M, Chidambaram JD, Alemayehu W, Lee DC, Yi EH, Cevallos V, Zhou Z, Donnellan C, Saidel M, Whitcher JP, Gaynor BD, Lietman TM. Feasibility of eliminating ocular chlamydia trachomatis with repeat mass antibiotic treatments. Jama. 2004;292:721-5.

18. University of Twente. Health Belief Model; 2013. https://www.utwente.n//en/ bms/communication-theories/sorted-bycluster/Health\%20Communication/ Health_Belief_Model/. Accessed 28 June 2013.

19. Desmond N, Solomon AW, Massae PA, Lema N, Anemona A, Foster A, Mabey DW. Acceptability of azithromycin for the control of trachoma in northern Tanzania. Trans R Soc Trop Med Hyg. 2005;99:656-63.

20. Lwanga SK, Lemeshow S. Sample size determination for health studies: a practical manual. Geneva: World Health Organization; 1991. p. 1-5.

21. Harding-Esch EM, Sillah A, Edwards T, Burr SE, Hart JD, Joof H, Laye M, Makalo P, Ahmed M, Molina S, Sarr-Sissoho I, Quinn TC, Lietman T, Holland MJ, Mabey D, West SK, Robin B. Mass treatment with azithromycin for trachoma: when is one round enough? Results from the PRET Trial in the Gambia. PLoS Negl Trop Dis. 2013;7:e2115. https://doi.org/10.1371/journal. pntd.0002115.

22. Central Statistics Authority. Summary and Statistical Report of the 2007 Population and Housing Census. 2008, Addis Ababa. https://searchworks. stanford.edu/view/8650186. Accessed 12 Dec 2012.

23. Cromwell EA, King JD, McPherson S, Jip FN, Patterson AE, Mosher AW, Evans DS, Emerson PM. Monitoring of mass distribution interventions for trachoma in plateau state, Nigeria. PLoS Negl Trop Dis. 2013;7:e1995. https://doi.org/10.1371/journal.pntd.0001995.

24. Malaty RR, Zaki SS, Said ME, Vastine DW, Dawson DW, Schachter J. Extra ocular infections in children in areas with endemic trachoma. J Infect Dis. 1981;143:853.

25. Blake IM, Burton MJ, Bailey RL, Solomon AW, West S, Munoz B, Holland MJ, Mabey DCW, Gambhir M, Basanez MG, Grassly NC. Estimating household and community transmission of ocular chlamydia trachomatis. PLoS Negl Trop Dis. 2009;3:e401. https://doi.org/10.1371/journal.pntd.0000401.

26. Lakew T, House J, Hong KC, Yi E, Alemayehu W, Melese M, Zhou Z, Ray K, Chin S, Romero E, Keenan J, Whitcher JP, Gaynor BD, Lietman TM. Reduction and return of infectious trachoma in severely affected communities in Ethiopia. PLoS Negl Trop Dis. 2009;3:e376. https://doi.org/10.1371/journal.pntd.0000376.
27. Grassly NC, Ward ME, Ferris S, Mabey DC, Bailey RL. The natural history of trachoma infection and disease in a Gambian cohort with frequent follow up. PLoS Negl Trop Dis. 2008;2:e341. https://doi.org/10.1371/journal.pntd. 0000341.

28. Taylor KI, Taylor HR. Distribution of azithromycin for the treatment of trachoma. Br J Ophthalmol. 1999:83:134-5.

29. Ayele B, Gebre T, House JI, Zhou Z, McCulloch CE, Porco TC, Gaynor BD, Emerson PM, Lietman TM, Keenan JD. Short report: adverse events after mass azithromycin treatments for trachoma in Ethiopia. Am J Trop Med Hyg. 2011;85:291-4.

30. FDA. United states Food and Drug Administration safety announcement; 2013. https://www.fda.gov/downloads/Drugs/DrugSafety/UCM343347.pdf. Accessed Dec 2013

31. Ray WA, Murray KT, Hall K, Arbogast PG, Stein CM. Azithromycin and the Risk of Cardiovascular Death. N Engl J Med. 2012; https://doi.org/10.1056/ NEJMoa1003833.

32. Bin Abdulhak AA, Khan AR, Garbati MA, Qazi AH, Erwin P, Kisra S, Aly A, Farid T, ElChamiM WAP. Azithromycin and risk of cardiovascular death: a Meta analytic review of observational studies. Am J Ther. 2015; https://doi.org/10.1097/MJT.0000000000000138.

33. Alemayehu D, Andrews EN, Glue P, Knirsch CA. Considerations for the design and conduct of a pharmacovigilance study involving mass drug Administration in a Resource-Constrained Setting. PLoS Negl Trop Dis. 2010; https://doi.org/10.1371/journal.pntd.0000564.

34. Amarillo MLE, Belizario WY, Sadiang-abay JT, Sison SAM, Dayag AMS. Factors associated with the acceptance of mass drug administration for the elimination of lymphatic filariasis in Agusan del Sur, Philippines. Parasit Vectors. 2008;1:14. https://doi.org/10.1186/1756-3305-1-14.

\section{Ready to submit your research? Choose BMC and benefit from:}

- fast, convenient online submission

- thorough peer review by experienced researchers in your field

- rapid publication on acceptance

- support for research data, including large and complex data types

- gold Open Access which fosters wider collaboration and increased citations

- maximum visibility for your research: over $100 \mathrm{M}$ website views per year

At $\mathrm{BMC}$, research is always in progress.

Learn more biomedcentral.com/submissions 